\title{
THE MALE OF ECHINOTHERIDION (ARANEAE: THERIDIIDAE)*
}

\author{
By Herbert W. LeVI \\ Museum of Comparative Zoology, Harvard University \\ Cambridge, Mass. 02138
}

Introduction. A genus based on specimens of one sex only is unsatisfactory, even when the available specimens are so distinctive as to demand description. The four described species of the genus Echinotheridion all are known from females only. It therefore is important to describe the male recently found, the more so in view of his remarkable features.

I would like to thank Norman Platnick, who found the male in American Museum of Natural History collections and recognized it as a possible male of Echinotheridion.

Echinotheridion are small theridiid spiders, 2 to $3 \mathrm{~mm}$ in total length. The carapace is like that of Achaearanea and Theridion. The anterior median eyes of the known species are larger than others, less than their diameter apart, almost touching the laterals. Eyes of the posterior row are equally spaced. Chelicerae are small with two anterior sclerotized teeth. Legs are short, the first longest. The abdomen is suboval, higher than long (Levi, 1963, fig. 120). There is no colulus. As in specimens of Tidarren, there usually is a vertical white line just above the spinnerets. Unusual for theridiid spiders is the enormous sclerotized epigynum. Overhanging the epigynum are coxal spurs which appear to be a functional part of the structure (Levi, 1963, fig. 120). Coxal spurs are otherwise uncommon in female theridiid spiders.

Four species are known, three new in 1963: E. cartum from southern Brazil, E. elicolum from Venezuela, E. otlum from Ecuador, and E. utibile (Keyserling) from the Amazon. The recently collected male comes from within the range of $E$. cartum and probably belongs to that species.

The male is remarkable in having only one palpus, and this of enormous size, similar to males of Tidarren. Upon attaining adulthood, Tidarren males attach one of their two palpi to a silk web and twist it off (Branch, 1942).

*Manuscript received by the editor April 2, 1981 

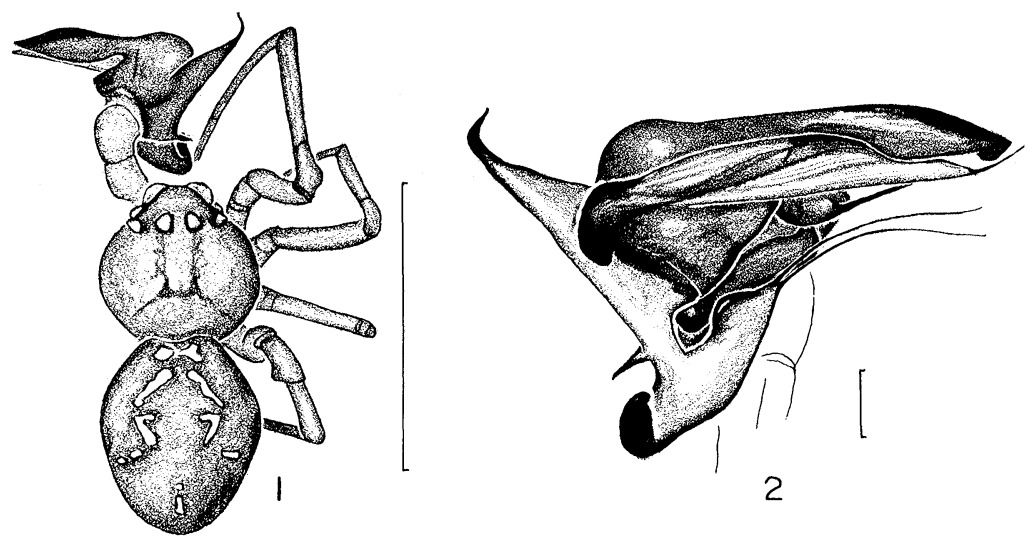

Figs. 1,2. Echinotheridion cartum. 1. Male, scale line $1.0 \mathrm{~mm}$. 2. Left palpus, scale line $0.1 \mathrm{~mm}$.

The second unusual feature is the highly modified cymbium(Fig. 2): two ends are drawn out into spines, while another side is pulled out and apparently supports the cymbium. Because the individual has only one palpus, I did not dissect or expand it, so the homology of the structures is not understood. An embolus can be seen below the lateral extension (on the right in Fig. 2).

Unlike the female, the male has no spurs on the fourth coxae and has no other leg modifications.

If the modified cymbium and the white mark above the spinnerets (Fig. 1) are synapomorphies, one must consider the genus related to Achaearanea and Tidarren.

\section{Echinotheridion cartum Levi \\ Figures 1 and 2}

Echinotheridion cartum Levi, 1963: 236, figs. 117-121, ㅇ, Map 3. Female holotype from Apa [River] Paraguay, 1908-1909 in the American Museum of Natural History.

Description. Male. Carapace golden yellow with dusky marks, darker on sides. Sternum gray. Legs dusky light brown. Dorsum of abdomen with white pigment spots as in figure. Venter gray. Posterior eyes 0.5 diameters of anterior medians. Anterior laterals 0.4 diameters of anterior median eyes. Anterior median eyes 0.6 
diameters apart, almost touching laterals. Posterior median eyes their diameter apart, their diameter from laterals. The height of the clypeus is slightly more than 2 diameters of anterior median eyes. The chelicerae are small and weak. Their length equals the height of the clypeus. The sternum is convex; the coxae are not modified. Total length, $1.22 \mathrm{~mm}$. Carapace, $0.59 \mathrm{~mm}$ long, $0.57 \mathrm{~mm}$ wide. First femur, $0.81 \mathrm{~mm}$; patella and tibia, $0.80 \mathrm{~mm}$; metatarsus, 0.65 $\mathrm{mm}$; tarsus, $0.45 \mathrm{~mm}$. Second patella and tibia, $0.62 \mathrm{~mm}$; third, 0.41 $\mathrm{mm}$; fourth, $0.61 \mathrm{~mm}$.

Record. Brazil. Mato Grosso: Sinop [12 $31^{\prime}$ S: $55^{\circ} 37^{\prime} \mathrm{W}$ ], October 1975, ô (M. Alvarenga, AMNH).

\section{Literature Cited}

BRANCH, J. H.

1942. A spider which amputates one of its palpi. Bull. South. California Acad. Sci., 41: 139-140.

LeVI, H. W.

1955. The spider genera Chrysso and Tidarren in America (Araneae: Theridiidae). J. New York Ent. Soc., 58: 59-81.

1963. American spiders of the genus Achaearanea and the new genus Echinotheridion (Araneae, Theridiidae). Bull. Mus. Comp. Zool., 129(3): 187-240. 

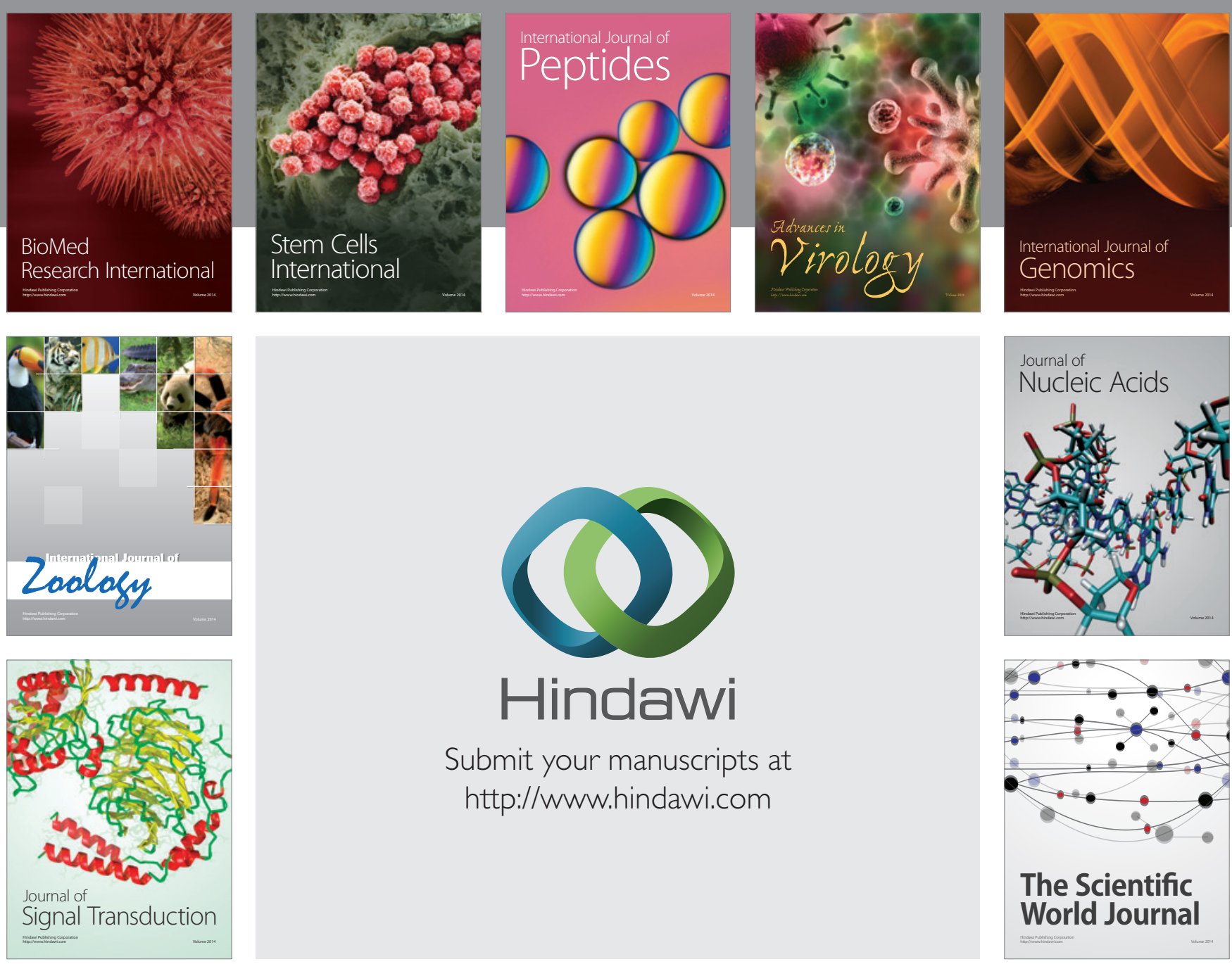

Submit your manuscripts at

http://www.hindawi.com
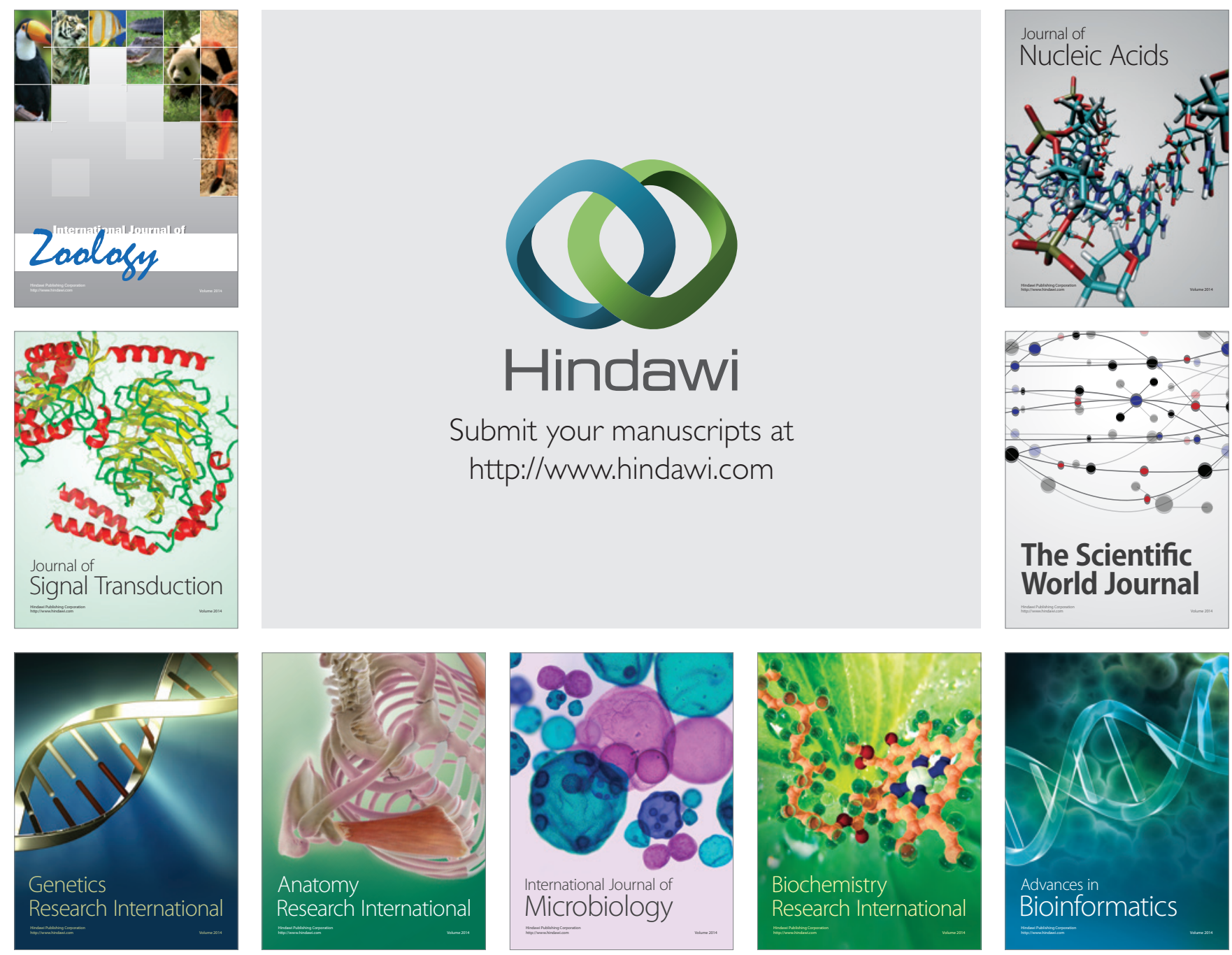

The Scientific World Journal
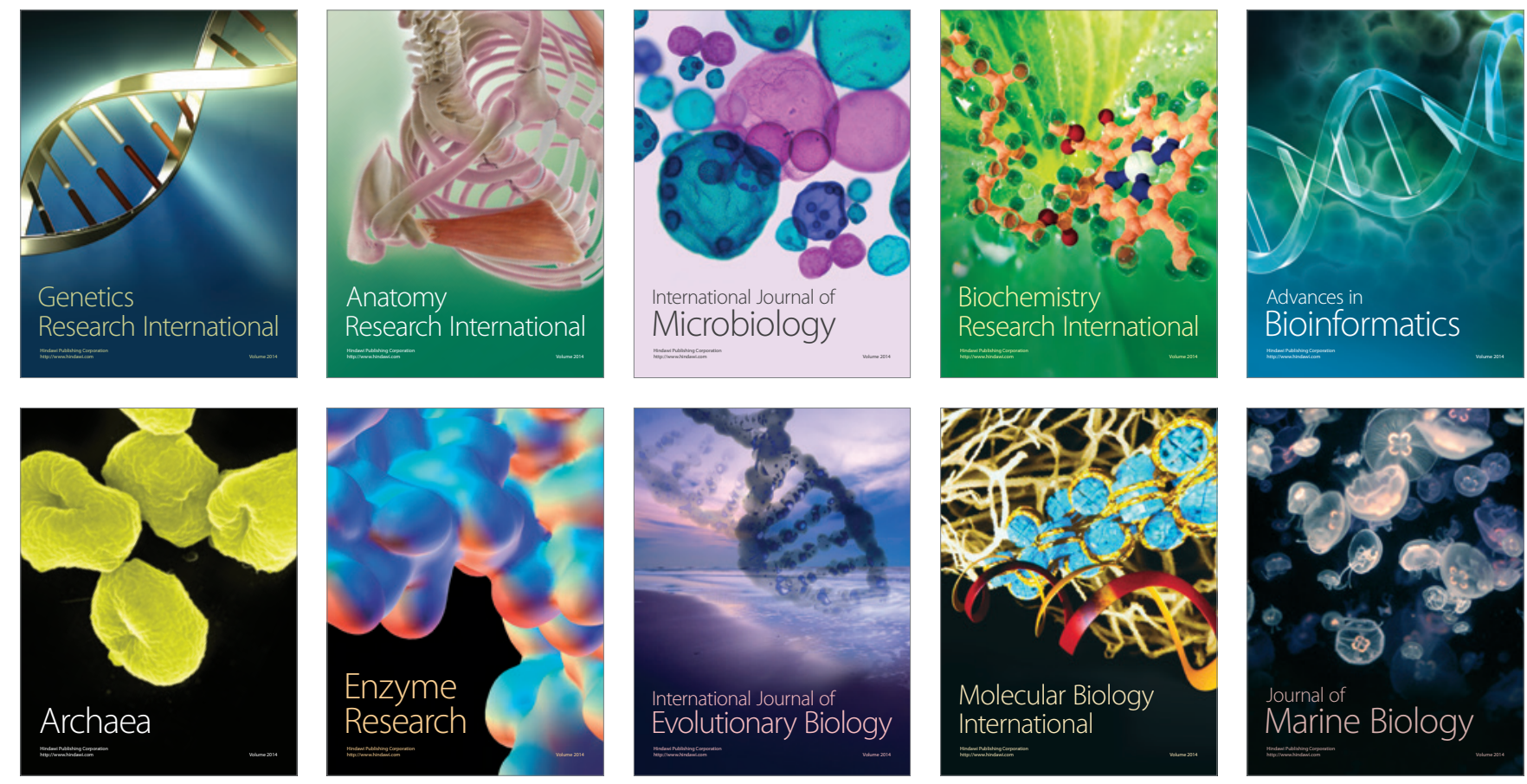